\title{
INFLUÊNCIA DA COBERTURA MORTA NA UMIDADE, INCIDÊNCIA DE PLANTAS DA- NINHAS E DE BROCA-DO-RIZOMA (Cosmopolites sordidus) EM UM POMAR DE BANA- NEIRAS (Musa spp.) ${ }^{1}$
}

\author{
CAMILO AUGUSTO PINTO DE OLIVEIRA² \& CAETANO MARCIANO DE SOUZA ${ }^{3}$
}

\begin{abstract}
RESUMO - O fato do Brasil possuir a maior área plantada do mundo com banana e ocupar apenas a segunda colocação no ranking mundial dos maiores produtores, revela a necessidade da adoção de técnicas de manejo que tenha por objetivo incrementar a produção. Os objetivos do presente trabalho foram avaliar os efeitos da cobertura morta sobre a umidade, incidência de plantas daninhas e da broca-do-rizoma em um pomar de bananeiras manejado com e sem cobertura morta. Os resultados obtidos revelaram que a cobertura morta proporcionou benefícios quanto à manutenção da umidade no solo e controle de plantas daninhas, porém, na incidência da broca, não houve diferença em relação à área conduzida sem cobertura morta. Termos para indexação: Banana, manejo do solo, mulching, ervas daninhas.
\end{abstract}

\section{EFFECT OF MULCHING ON HUMIDITY, WEEDS AND Cosmopolites sordidus ON BANANAS (Musa spp.) ORCHARD}

ABSTRACT - Brazil possesses the largest harvest area of banana in the world, however it just occupies the second placement in the world ranking of the largest producers. For this reason, handling techniques should be used purposing to increase the productivity. This work aimed to evaluate the effects of mulching on humidity, weeds and Cosmopolites sordidus in a banana orchard managed with mulching and without mulching. The analysis and interpretation of results showed that the mulching presented benefits related to the soil humidity maintenance and weeds control, and the incidence of the Cosmopolites sordidus did not show any difference compared with the maintained area without mulching.

Index Terms: Banana, soil management, mulching, Cosmopolites sordidus, weed control.

O Brasil possui a maior área plantada do mundo com banana (518 mil hectares), entretanto, ocupa apenas a segunda colocação no ranking mundial dos maiores produtores, com uma produção de 5,6 milhões de toneladas ao ano (FAO, 2000). Um dos motivos para a ocorrência de tal fato é o avançado estágio de degradação dos solos, sendo necessária a adoção de práticas conservacionistas para minimizar seu desgaste e manter sua produtividade.

Segundo Jalota \& Prihar (2000), a prática da cobertura morta consiste em cobrir o solo com capim, palha, casca, papel, plástico e outros. É recomendada para praticamente todos os solos, todos os climas e todas as culturas perenes, sendo inúmeros os benefícios por ela trazidos (Borges et al., 1995). Dentre eles pode-se citar a proteção do solo contra o impacto das gotas de chuva, que obstruem os poros implicando em perda de aeração, aumento de adensamento e escorrimento superficial - carreando as partículas do solo-, resultando em redução de sua fertilidade (Bertoni \& Lombardi Neto, 1990).

A utilização da bananeira para formação da cobertura morta representa uma fonte substancial de matéria orgânica, através dos resíduos constituídos por toda a planta após a colheita do cacho, pelas folhas secas provenientes das desfolhas e pelo rizoma e raízes que se decompõem no solo (Borges \& Souza, 1998b), estimulando a proliferação de microrganismos, melhorando a aeração e a estrutura do mesmo (Borges et al., 1997). Contudo, devido à sua decomposição acelerada, este volume de resíduos é insuficiente para a formação de uma cobertura contínua e efetiva (International..., 1990). Uma solução testada na Embrapa Mandioca e Fruticultura consiste na implantação de um pequeno bananal, contíguo à área de produção definitiva, para suprir os resíduos vegetais necessários. Para tal, deve-se adensar ao máximo o plantio e usar variedades regionais de crescimento rápido, de elevada produção de massa verde e resistentes às principais pragas e doenças (Alves, 1997).

Segundo Borges \& Souza (1998a), a bananeira é uma planta que restitui ao solo grande parte dos nutrientes extraídos pela cultura por meio de sua massa vegetativa, uma vez que $66 \%$ dessa biomassa retornam ao solo na forma de pseudocaules e folhas. Resultados obtidos por Borges (1991), em amostras de solo coletadas 18 meses após a instalação do ensaio, mostraram que o uso da cobertura morta melhorou a fertilidade do mesmo, especialmente os teores de potássio e cálcio, soma de bases, CTC, saturação por bases e matéria orgânica, com aumentos percentuais da ordem de $139 \%, 183 \%, 140 \%, 21 \%, 100 \%$ e $12 \%$, respectivamente, em relação ao manejo com capina. Além disso, foram observados teores mais altos de nutrientes nas folhas das bananeiras sob cobertura morta, com exceção de N, Cu, Fe e Mn, com destaque para o teor de K, maior em cerca de $94 \%$ em relação à capina.

A bananeira é uma planta muito exigente em água, que requer uma grande e permanente disponibilidade da mesma no solo. Ao sofrer deficiência hídrica, mesmo que pequena, a cultura não se desenvolve satisfatoriamente, afetando a produtividade e a qualidade do fruto. Cintra (1988), estudando o balanço de água no solo em Cruz das Almas, BA, nos meses de baixa precipitação (setembro a dezembro), observou que a cobertura morta proporciona maior conservação da umidade, superando em $180 \%$ à da cobertura do solo com vegetação natural e em $92 \%$ à do solo capinado manualmente.

O uso da cobertura morta apresenta o inconveniente da mesma ser um atrativo à broca-do-rizoma (Cosmopolites sordidus). Mesquita et al., (1983) observaram que o número de insetos capturados durante três ciclos de produção foi maior em parcelas mantidas com cobertura morta constituída de partes da própria bananeira, em comparação com parcelas mantidas com Canavalia ensiformis, Crotalaria retusa, Leucena leucocephala, Glycine javanica, cobertura natural, capina e herbicida. A broca-do-rizoma é a principal praga da bananeira, sendo encontrada praticamente em todas as regiões onde é cultivada, provocando perdas que podem chegar a $80 \%$. Além dos danos diretos, o ataque da broca facilita a penetração de outros insetos, de nematóides e de agentes patogênicos (Alves, 1997).

O objetivo do trabalho foi avaliar a influência da cobertura morta no percentual de água, plantas daninhas e broca-do-rizoma na cultura da bananeira, comparando uma área conduzida com cobertura morta, com uma conduzida sem cobertura morta.

O experimento foi conduzido no município de Visconde do Rio Branco, MG, a $349 \mathrm{~m}$ de altitude, com temperatura média anual de $21,7^{\circ} \mathrm{C}$ $\left(29,1^{\circ} \mathrm{C}\right.$ de máxima e $16,3^{\circ} \mathrm{C}$ de mínima), umidade relativa do ar média de $79,5 \%$ e precipitação média anual de $1.272 \mathrm{~mm}$. O solo é um Podzólico Vermelho-Amarelo Câmbico, Fase Terraço, de topografia plana.

O delineamento experimental utilizado foi o inteiramente

\footnotetext{
(Trabalho 175/2002). Recebido: 21/08/2002. Aceito para publicação: 30/05/2003.

${ }^{2}$ Eng. Agr., Estudante de Pós-Graduação da Universidade Federal de Viçosa. R. Clodoaldo costa, 16, Cx 101, Cruz das Almas-BA, CEP 44380-000. Tel. (75) 621-2468/ 1768. e-mail camiloaugusto@ hotmail.com.

${ }^{3}$ Eng. Agr., D.S., Professor do Dep. de Fitotecnia da Universidade Federal de Viçosa, CEP 36571-000, Viçosa-MG.
} 
casualizado, com dois tratamentos e 10 repetições (Banzatto \& Kronka, 1989). Um tratamento constituiu-se pela condução do pomar com cobertura morta (restos vegetais da própria cultura) e o outro pela condução sem cobertura morta (por meio da capina manual). Cada unidade experimental foi composta por 10 plantas úteis, com espaçamento de $2 \mathrm{~m}$ entre plantas e $3 \mathrm{~m}$ entre fileiras. O total de plantas no experimento foi 288 , sendo 200 úteis e o restante (88) bordadura.

A umidade foi avaliada conforme metodologia descrita pela EMBRAPA (1997); a coleta de dados iniciou-se quinze dias após a capina, seguindo este mesmo intervalo de tempo para as coletas posteriores, num total de quatro, para avaliar-se o comportamento da umidade no solo nas camadas de $0-5,5-10,10-20$ e $20-40 \mathrm{~cm}$ de profundidade. A infestação de plantas daninhas foi avaliada pelo método do quadrado, que consiste em lançar aleatoriamente um quadrado de $1 \mathrm{~m}$ de lado, realizando a contagem das mesmas ali contidas, com avaliações em intervalos de 15 dias. Para a avaliação da infestação da broca-do-rizoma foram elaboradas iscas tipo "telha" (fragmentos com 40-60 cm de pseudocaule, seccionados ao meio longitudinalmente), colocando-se duas por unidade experimental. Efetuou-se a contagem dos insetos 15 dias após a colocação das iscas, conforme indicado por Salomão et al., (1998).

As Figuras 1 e 2 retratam a dinâmica da umidade no perfil do solo durante 60 dias de avaliação. Pode-se observar que em ambos os tratamentos houve decréscimo da umidade ao longo do tempo, com exceção da avaliação aos 30 dias, fato explicado pela ocorrência de uma precipitação de $70 \mathrm{~mm}$ entre o $15^{\circ}$ e o $30^{\circ}$ dia de avaliação. A perda de umidade mostrou-se mais acentuada no tratamento sem cobertura morta (Figura 2), principalmente nas camadas superficiais, ao longo do tempo de avaliação.

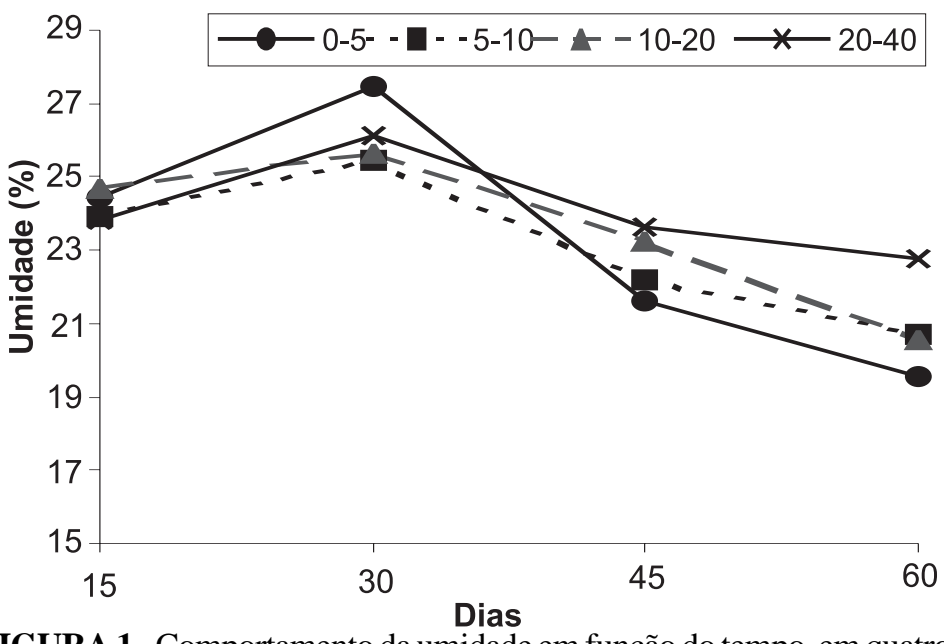

FIGURA 1 - Comportamento da umidade em função do tempo, em quatro profundidades avaliadas (em centímetros), no tratamento com cobertura morta.

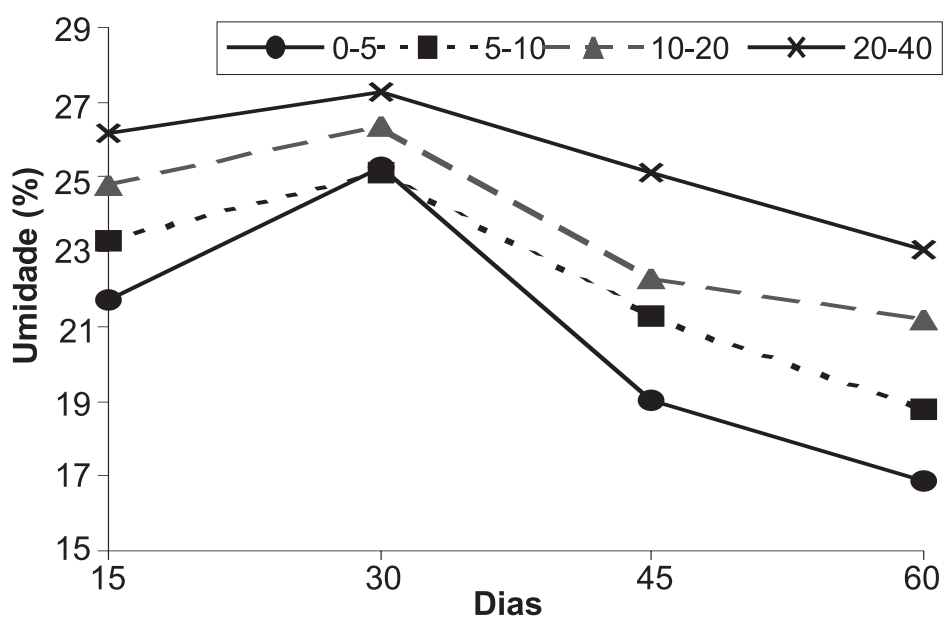

FIGURA 2 - Comportamento da umidade em função do tempo, em quatro profundidades avaliadas (em centímetros), no tratamento sem cobertura morta.
Na avaliação feita aos 30 dias, observou-se que, na camada de $0-5 \mathrm{~cm}$ de profundidade, o teor de umidade no tratamento com cobertura morta mostrou-se superior. Isto se explica pelo fato de que os restos vegetais promovem uma retenção da água na sua estrutura, liberando-a gradativamente ao solo e deixando-o mais úmido na camada superficial - por se encontrar em contato direto com os mesmos. Observou-se também que com o passar do tempo a camada de 20-40 cm apresentou um teor de umidade superior às demais nos dois tratamentos; as forças de gravidade e a falta de chuva dos 30 aos 60 dias de avaliação parecem ser as principais causas dessas observações. Comparando-se as Figuras 3 e 4, pode-se observar uma maior uniformidade na distribuição de água ao longo do perfil do solo manejado com cobertura morta, em contraposição ao outro manejo, onde as camadas superiores perdem água facilmente por evaporação. A Figura 4 evidencia a perda de água no manejo do solo desnudo, principalmente na camada superficial, contrapondo com a Figura 3, onde pode-se observar a manutenção da água na mesma camada.

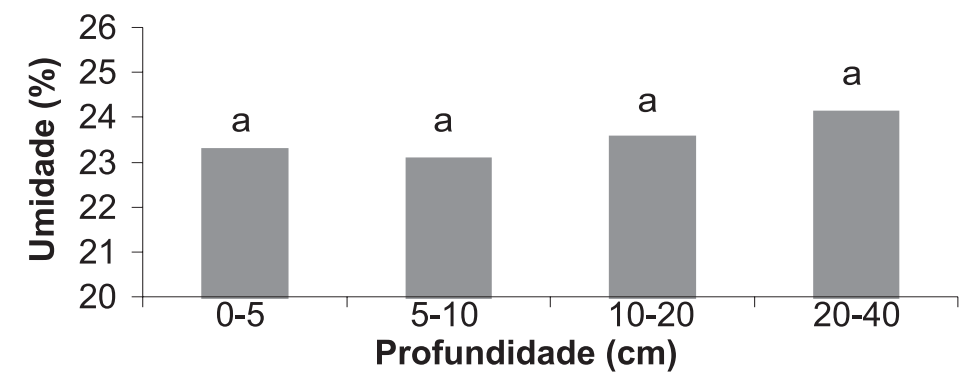

FIGURA 3 - Médias de umidade ao longo do perfil do solo, no tratamento com cobertura morta.

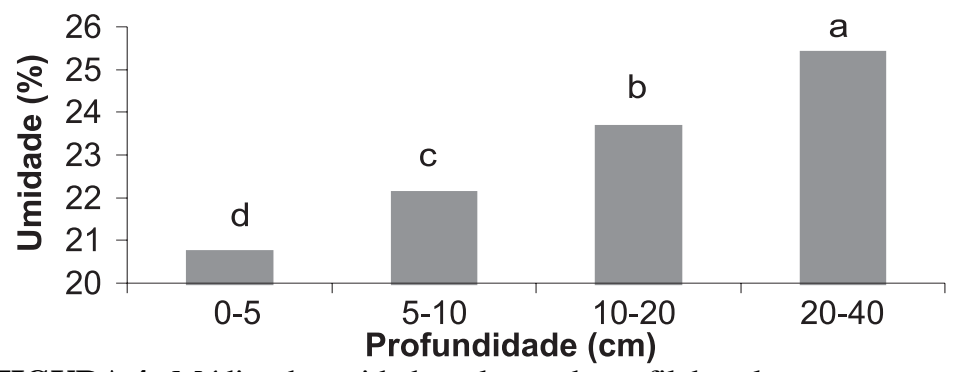

FIGURA 4 - Médias de umidade ao longo do perfil do solo, no tratamento sem cobertura morta.

Constatou-se também que a camada de $20-40 \mathrm{~cm}$ de profundidade, no tratamento sem cobertura morta, apresentou teor de umidade mais elevado que a do outro tratamento. A ausência de barreiras (restos vegetais) evita a retenção da água na superfície, que se infiltra (quando não há escorrimento superficial) acumulando-se nas camadas inferiores.

O efeito benéfico da cobertura morta sobre o controle de plantas daninhas confirmou-se neste experimento, revelando valores discrepantes quando comparados os dois tratamentos (Figura 5). Este resultado é conseqüência do efeito do "mulch" sobre o solo, que impede, ou reduz, o contato dessas plantas com os raios solares, conseqüentemente evitando a germinação das sementes e o desenvolvimento das ervas.

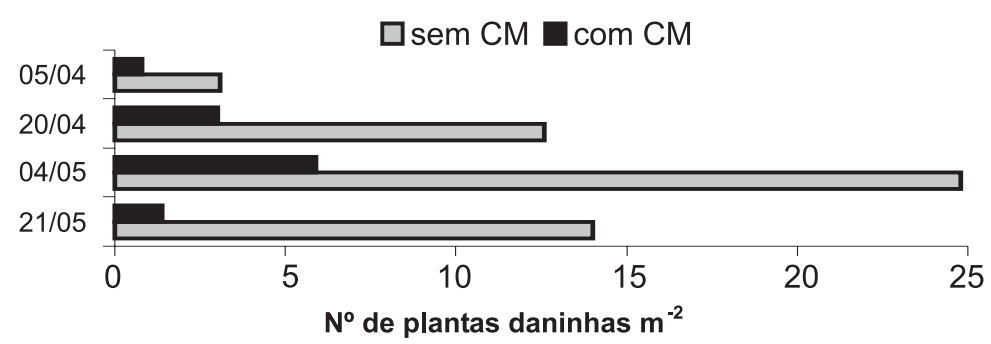

FIGURA 5 - Número de plantas daninhas amostradas por metro quadrado nos tratamentos em estudo. 
Quanto à incidência da broca-do-rizoma, houve um decréscimo progressivo no número de insetos em ambos os tratamentos, já que os insetos coletados na contagem foram retirados da área, evidenciando a eficiência da isca. Na Figura 6 pode-se observar que no final das avaliações, a área que antes era mais povoada apresentou menor número de insetos, revelando que a cobertura morta é um atrativo para o mesmo; entretanto essa diferença não foi significativa, podendo-se concluir que a cobertura morta não interferiu significativamente na incidência de broca, no período em estudo.

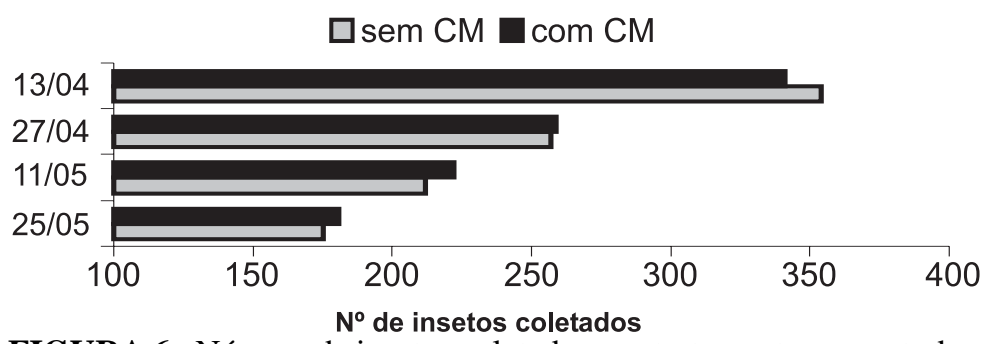

FIGURA 6 - Número de insetos coletados nos tratamentos em estudo.

Pode-se concluir que o tratamento com cobertura morta proporcionou melhor conservação da umidade nas camadas mais superficiais do solo e foi mais eficiente no controle das plantas daninhas. Quanto à incidência de brocas não houve diferença entre os tratamentos

\section{REFERÊNCIASBIBLIOGRÁFICAS}

ALVES, E. J. (Org.) A cultura da banana: aspectos técnicos, socioeconômicos e agroindustriais. Brasília: Embrapa-SPI/Cruz das Almas: Embrapa-CNPMF, 1997. 585 p.

BANZATTO, D. A.; KRONKA, S. N. Experimentação agrícola. Jaboticabal, SP: FUNEP, 1989.247p.

BERTONI, J.; LOMBARDI NETO, F. Conservação do solo. São Paulo, SP: Ed. Ícone, 1990.355p.

BORGES, A. L. Influência da cobertura morta nas características químicas do solo e na produção da bananeira. Cruz das Almas, BA: EMBRAPA-CNPMF, 1991.6p. (C. T. 19).
BORGES, A. L.; SOUZA, L. da S. Alteração de propriedades físicas do solo sob diferentes coberturas vegetais no cultivo da bananeira. Fortaleza, CE. In: REUNIÃO BRASILEIRA DE MANEJO E CONSERVAÇÃO DO SOLO E DA ÁGUA, 13., 1998a., Fortaleza. Resumos... p.93-94.

BORGES, A. L.; SOUZA, L. da S. Cobertura vegetal Del suelo para el banano. In: REUNION ACORBAT, 13., 1998b., Equador. p.608-617.

BORGES, A. L.; SOUZA, L. da S.; ALVES, E. J. Coberturas vegetais do solo: efeito sobre suas propriedades químicas e o desenvolvimento vegetativo da bananeira - primeiro ciclo. Cruz das Almas, BA: EMBRAPA-CNPMF, 1997. 4p. (Pesquisa em Andamento, 43).

BORGES, A. L.; SOUZA, L. da S.; FANCELLI, M.; ALVES, E. J.; CALDAS, R. C.; SOUZA, J. da S. Cobertura vegetal na melhoria das propriedades químicas e físicas dos solos e na produção da bananeira. Cruz das Almas, BA: EMBRAPA-CNPMF, 1995. 6p. (Pesquisa em Andamento, 29).

CINTRA, F. L. D. Manejo e conservação do solo em bananais. Revista brasileira de Fruticultura, Cruz das Almas, v.10, n.1, p.65-73, 1988.

EMBRAPA. CENTRO NACIONAL DE PESQUISA DE SOLOS. Manual de métodos de análise de solo. 2. ed. Rev. Atual. Rio de Janeiro, 1997. $212 p$.

FAO - FOOD AND AGRICULTURE ORGANIZATION. Disponível em:<http://apps.fao.org/cgi-bin/nph-db.pl>. Acesso em: 22 março 2000.

INTERNATIONAL INSTITUTE OF TROPICAL AGRICULTURE. Plantain cultivation under west African conditions - a reference manual. Ibadan, Nigeria. 1990.24p.

JALOTA, S. K.; PRIHAR, S. S. Hardcover. Site barnesandnoble. Iowa State University, 1998. Disponível em: <http:// shop.barnesandnoble.com/booksearsh/isbnInquiry.asp?>.

MESQUITA, A. L. M.; CINTRA, F. L. D.; CALDAS, R. C. Evolução e danos de Cosmopolites sordidus em bananeira 'Prata' submetida a diferentes práticas de manejo. Cruz das Almas, BA: EMBRAPACNPMF, 1983. 4p. (Pesquisa em Andamento, 29).

SALOMÃO, L. C. C.; SIQUEIRA, D. L. de; MOTOIKE, S. Y. Cultura da bananeira. Viçosa, MG: UFV, 1998. 38p. (Cadernos didáticos, 25). 